\title{
Cerebral Metastases from Malignant Melanoma
}

\author{
Ivar M. Mendez and Rolando F. Del Maestro
}

\begin{abstract}
Six hundred and fifty-two patients with histologically proven primary malignant melanoma have been followed by the London Regional Cancer Centre from 1960 to 1985 . Neurological signs and symptoms secondary to metastases to the brain developed in fifty-five patients $(8.4 \%)$. The median age was 49 years; $71 \%$ were male and $29 \%$ female. Multiple lesions were found in $61 \%$ and a single metastasis in $39 \%$. The most common site for the primary lesion was the trunk in males (44\%) and the lower limb in females $(37 \%)$. Six month survival for patients with a single metastasis was $58 \%$ if surgical excision was possible and $25 \%$ of these patients survived greater than two years. In patients with multiple metastases that received radiotherapy, survival times of greater than six months were found in $12 \%$ of the patients. Patients with a single metastasis appear to benefit by being managed by surgical removal of the lesion.
\end{abstract}

\begin{abstract}
RÉSUMÉ: Des métastases cérébrales du mélanome malin. Nous avons surveillé 652 patients atteints de mélanome malin primaire mis en évidence par la preuve histologique au London Regional Cancer Centre de 1960 jusqu'à 1985. Des trouvées et symptômes neurologiques provenant de métastases au cerveau apparurent chez 55 patients (8,4 pour cent). L'âge médien était de 49 ans; soixante et onze pour cent d'entre eux étaient patients de sexe masculin et 29 pour cent patients de sexe feminin. Des lésions multiples ont été trouvées dans 61 pour cent des cas et une métastase unique a été démontrée dans 39 pour cent. Le lieu le plus fréquent de la lésion primaire était dans le tronc du corps chez les hommes ( 44 pour cent) et dans les membres inférieurs chez les femmes ( 37 pour cent). Une survie de six mois chez les patients atteints d'une seule métastase était de 58 pour cent lorsqu'une excision chirurgique a été possible, vingt-cinq pour cent de ces patients survécurent plus de deux ans. Chez les patients atteints de métastases multiples ceux qui ont reçu la radiothérapie, une période de survie de plus de six mois en a été montrée dans 12 pour cent. Les patients atteints d'une métastase unique semblent bénéficier d'une excision chirurgique de la lésion.
\end{abstract}

Can. J. Neurol. Sci. 1988; 15:119-123

Although malignant melanoma is rare $(4.2 / 100,000$ population) and accounts for only $1 \%$ of all types of cancer in North America, it represents, after carcinoma of the bronchus and breast, the third most common cause for central nervous system (CNS) metastases. ${ }^{1,2,3}$ Metastatic malignant melanoma of the CNS is the most common cause of death in malignant melanoma patients. ${ }^{4,5}$ The natural history of the disease is unpredictable making determinations of the effectiveness of specific treatment for CNS metastasis difficult. Metastases to the CNS occur at variable times after the diagnosis of the primary lesion. The interval appears to be related to the anatomical location of the primary neoplasm. ${ }^{6}$ Once cerebral metastases become symptomatic, the patient usually succumbs within a few months ${ }^{7}$ although longer survival has been reported. ${ }^{8,9}$ The aim of this study was to analyze the malignant melanoma population with cerebral metastases and to develop a rational concept of therapy.

\section{Patients ANd Methods}

The study group consisted of 652 patients with histologically proven cutaneous malignant melanoma who were seen at the London Regional Cancer Centre from 1960 through 1985. Data was collected retrospectively from the patient's charts using a standardized protocol specially designed for this study. Patients with cerebral metastases presenting with neurological signs and symptoms were divided in two groups. The first group included patients with single metastases and the second group consisted of patients with multiple metastases. Each of these two groups were further subdivided according to the treatment received. Patient follow up was carried out until the time of death. One patient was still alive at the study end point. Diagnosis of cerebral metastases was based on the clinical history, neurological examination, isotope brain scan, cerebral angiography and computerized tomography (CT).

From the Brain Research Laboratories, Clinical Research Unit, Department of Clinical Neurological Sciences, Victoria Hospital, London

Received October 6, 1987. Accepted in final form March 3, 1988

Reprint requests to: Dr. R.F. Del Maestro, Brain Research Laboratory, Victoria Hospital, 375 South Street, London, Ontario, Canada N6A 4G5 
Determination of the cause of death was based on autopsy reports, clinical chart review and information obtained from the patient's family physician. In 38 patients with clinically symptomatic metastases (69\%), an autopsy confirmed the cause of death. In the remaining $17(31 \%)$, records pertaining to the clinical assessment of the patient near the time of death were used. In each case, the cause of death was reviewed and a determination made as to the role played by cerebral metastases from malignant melanoma. ${ }^{10} \mathrm{~A}$ number of treatment modalities were used in these patients. Surgical intervention involved the attempted removal of the metastatic lesion and, when feasible, a lobectomy or modified lobectomy was used. Radiation treatment consisted of a two week course of Cobalt -60 radiotherapy using a mean dose of $30 \mathrm{~Gy}$. A variety of chemotherapeutic agents were used including dimethyltrianzenoimidazole carboxamide (DTIC) and nitrosourea.

\section{ReSUltS}

\section{Patient population}

The series included 652 malignant melanoma patients seen from 1960 through $1985 ; 316$ (52.9) were male and 281 (47.1\%) were female. Fifty-five patients $(8.4 \%)$ developed neurological signs and symptoms related to cerebral metastases, $34(71 \%)$ of these were male and $16(19 \%)$ were female. The median age of presentation for patients with cerebral symptoms was 49 years (range 23-78). Females presented at a median age of 50 years (range 23-78) while the male median is 44 years (range 24-75). Multiple cerebral metastases were found in 33 patients $(61 \%)$ and 22 (39\%) had a single lesion (Table 1).

Autopsy information was available on 75 of the 301 patients who died. In $6(8 \%)$, evidence for malignant melanoma was found in multiple organs, but no cerebral lesion was identified. Cerebral metastases not clinically evident during life were identified in 31 (41\%). Thirty-eight of the 55 patients (69\%) with symptomatic cerebral metastases had autopsies and residual tumour was identified in all cases.

\section{Primary site}

In males, the primary lesions were more frequently encountered on the head, neck and trunk while, in females, the primary lesions were frequently on the limbs. The most common location of the primary lesion was the trunk for males (44\%) and the lower limb for females (37\%) (Table 2).

Table 1: Distribution of Patients By Age and Sex

\begin{tabular}{lcrrrrr}
\hline $\begin{array}{c}\text { Patients Without } \\
\text { CNS Metastases }\end{array}$ & \multicolumn{4}{c}{$\begin{array}{c}\text { Patients with } \\
\text { CNS Metastases }\end{array}$} \\
\hline Age (yr) & No. Cases & $\%$ & $\begin{array}{c}\text { Single } \\
\text { No. Cases }\end{array}$ & $\%$ & $\begin{array}{c}\text { Multiple } \\
\text { No. Cases }\end{array}$ & $\%$ \\
\hline $0-15$ & 4 & 1 & 0 & 0 & 0 & 0 \\
$16-34$ & 123 & 21 & 5 & 23 & 4 & 12 \\
$35-54$ & 272 & 46 & 14 & 64 & 17 & 52 \\
$55-74$ & 182 & 31 & 3 & 13 & 10 & 30 \\
$75-$ & 16 & 2 & 0 & 0 & 2 & 6 \\
\hline Total & 597 & 100 & 22 & 100 & 33 & 100 \\
Sex & & & & & & \\
Male & 316 & 53 & 15 & 68 & 24 & 73 \\
Female & 281 & 47 & 7 & 32 & 9 & 27 \\
Total & 597 & 100 & 22 & 100 & 33 & 100 \\
\hline & & & & & &
\end{tabular}

Time relationship between primary lesion and CNS metastases

The median time elapsed between initial diagnosis and secondary cerebral lesions varied according to the distance from the primary lesion to the brain - head 28 months; neck 27 months; upper limb 36 months; trunk 45 months and lower limb 78 months (Table 3 ). The most common sites for single CNS metastases was either the left $(30 \%)$ or the right $(15 \%)$ parietal lobe. In patients with multiple metastases, both hemispheres were involved in $58 \%$ of cases (Table 4).

\section{Presentation}

The most common presenting symptom for both single and multiple lesions was headache, occurring in 32 patients $(63 \%)$. Progressive hemiparesis occurred in 25 patients (45\%), seizures in 17 cases $(30 \%)$. Confusional states were more common in patients with multiple metastasis (Table 5). Intracranial hemorrhage as the mode of presentation occurred in 15 patients (27\%). None of the patients presented with carcinomatous meningitis. One patient developed carcinomatous meningitis several months after the initial presentation.

\section{Treatment}

Table 6 outlines the type of treatment received. In patients with single metastases, surgical resection of the tumour was the most common treatment, 12 patients $(54 \%)$, followed by a combination of surgery and postoperative radiotherapy in six

\begin{tabular}{lrrrrrrr}
\hline \multicolumn{7}{l}{ Table 2: Primary Site of Malignant Melanoma By Sex } \\
\hline \hline & Males & \multicolumn{1}{c}{$\%$} & Females & $\%$ & Total & $\%$ \\
\hline Head & 7 & 18 & 1 & 6 & 8 & 15 \\
Neck & 3 & 8 & 0 & 0 & 3 & 5 \\
Upper Limb & 4 & 10 & 3 & 19 & 7 & 13 \\
Trunk & 17 & 44 & 3 & 19 & 19 & 34 \\
Lower Limb & 4 & 10 & 6 & 37 & 11 & 20 \\
Other (not found) & 4 & 10 & 3 & 19 & 7 & 13 \\
\hline Total & 39 & 100 & 16 & 100 & 55 & 100 \\
\hline
\end{tabular}

\begin{tabular}{lcc}
\hline Table 3: Median Time From Primary Lesion to CNS Presentation \\
\hline \hline & $\begin{array}{c}\text { Time } \\
\text { Months }\end{array}$ & $\begin{array}{c}\text { Range } \\
\text { Months }\end{array}$ \\
\hline Site & 28 & $9-120$ \\
Head & 27 & $6-36$ \\
Neck & 45 & $12-204$ \\
Trunk & 36 & $12-72$ \\
Upper Limb & 78 & $24-84$ \\
Lower Limb & 78 & \\
\hline
\end{tabular}

\begin{tabular}{lccccrrr}
\hline \multicolumn{7}{l}{ Table 4: Site of Malignant Melanoma In The CNS } \\
\hline \hline \multicolumn{7}{c}{ Single } & \multicolumn{2}{c}{ Multiple } \\
Site & No. Cases & $\%$ & No. Cases & $\%$ & Total & $\%$ \\
\hline Frontal lobe & 3 & 14 & 2 & 6 & 5 & 9 \\
Parietal lobe & 10 & 45 & 12 & 36 & 22 & 40 \\
Occipital lobe & 5 & 22 & 0 & 0 & 5 & 9 \\
Temporal lobe & 3 & 14 & 0 & 0 & 3 & 5 \\
Both hemispheres & 0 & 0 & 19 & 58 & 19 & 34 \\
Cerebellum & 1 & 5 & 0 & 0 & 1 & 3 \\
\hline Total & 22 & 100 & 33 & 100 & 55 & 100 \\
\hline
\end{tabular}


Table 5: Clinical Presentation of Malignant Melanoma Metastases In The CNS

\begin{tabular}{lrrrrrr}
\hline \hline & \multicolumn{2}{c}{ Single } & \multicolumn{2}{c}{ Multiple } & \multicolumn{2}{c}{ Totals $\%$} \\
\hline Headaches & 15 & 36 & 18 & 26 & 33 & 30 \\
Hemiparesis & 10 & 24 & 15 & 21 & 25 & 22 \\
Seizures & 6 & 15 & 11 & 16 & 17 & 15 \\
Visual Dis. & 2 & 5 & 1 & 1 & 3 & 3 \\
Hemiplegia & 1 & 2 & 1 & 1 & 2 & 2 \\
Speech Dis. & 2 & 5 & 3 & 5 & 5 & 4 \\
Confusion & 2 & 5 & 11 & 16 & 13 & 12 \\
Dizziness & 2 & 5 & 1 & 1 & 3 & 3 \\
Memory loss & 1 & 3 & 3 & 5 & 4 & 4 \\
Abnormal behavior & 0 & 0 & 1 & 1 & 1 & 1 \\
Others & 0 & 0 & 5 & 7 & 5 & 4 \\
Total & & 100 & & 100 & & 100 \\
\hline
\end{tabular}

Table 6: Type of Therapy of Malignant Melanoma Metastases

\begin{tabular}{lcrrrrr}
\hline \hline & Single & $\%$ & Multiple & $\%$ & Total & $\%$ \\
\hline Surgery & 12 & 54 & 1 & 3 & 13 & 24 \\
Radiotherapy & 1 & 5 & 24 & 73 & 25 & 45 \\
Chemotherapy & 0 & 0 & 1 & 3 & 1 & 2 \\
Surg. + Rad. & 6 & 27 & 1 & 3 & 7 & 13 \\
Surg. + Rad. + Chemo. & 2 & 9 & 0 & 0 & 2 & 4 \\
Rad. + Chemo. & 0 & 0 & 3 & 9 & 3 & 5 \\
No treatment & 1 & 5 & 3 & 9 & 4 & 7 \\
\hline Total & 22 & 100 & 33 & 100 & 55 & 100 \\
\hline
\end{tabular}

cases (27\%). Radiotherapy was the most common treatment modality used in patients with multiple lesions; it was employed in 24 patients $(73 \%)$. In three patients $(9 \%)$ with multiple metastases, a combination of radiotherapy and chemotherapy was used (Table 6).

\section{Survival}

Median survival times for patients with single metastases after surgical resection was 5.5 months (range 1-64 + months). Seven patients $(58 \%)$ survived six months or more and three (25\%) survived more than 24 months. One is still alive at 64 months. When surgery and postoperative radiation were used in combination, possibly because of the surgeon's concern about incomplete surgical removal, the median survival was 3.0 months (range 1-28 months); two of the patients (33\%) survived six months or more and one patient (17\%) survived more than 24 months ( 28 months). For the 24 patients with multiple lesions who received radiotherapy alone, the median survival was 2.5 months (range 1-9.5 months) with only three of the patients (12\%) surviving longer than six months; no patient survived longer than 9.5 months (Figures 1 and 2). For patients that received other types of treatment or no treatment (Table 6), the median survival was 2.0 months (range 0.5-5 months).

\section{Cause of death}

Progressive neurological deterioration secondary to the malignant melanoma metastases was the cause of death in 36 patients $(65 \%)$. Fourteen patients ( $26 \%$ ) died of combined neurological and systemic causes. Five patients ( $9 \%$ ) died of systemic disease secondary to melanoma metastases to sites other than the brain.

\section{Discussion}

In the natural history of malignant melanoma, cerebral involvement is usually a terminal event. In this series, cerebral metastases were found in $92 \%$ of autopsied patients. In patients with symptomatic cerebral metastases, the cerebral disease contributed to the cause of death in $91 \%$. Cerebral metastases occur more frequently in males $(71 \%)$ than females $(29 \%)$ although the distribution of primary melanoma by sex is similar $(53 \%$ in males and $47 \%$ in females). The higher incidence of brain metastases in males may be related to the higher percentage of rapidly metastasizing head, neck and trunk primary lesions in this sex. ${ }^{11,12}$

A number of studies have indicated that surgery, radiotherapy and chemotherapy used alone or in combination have little

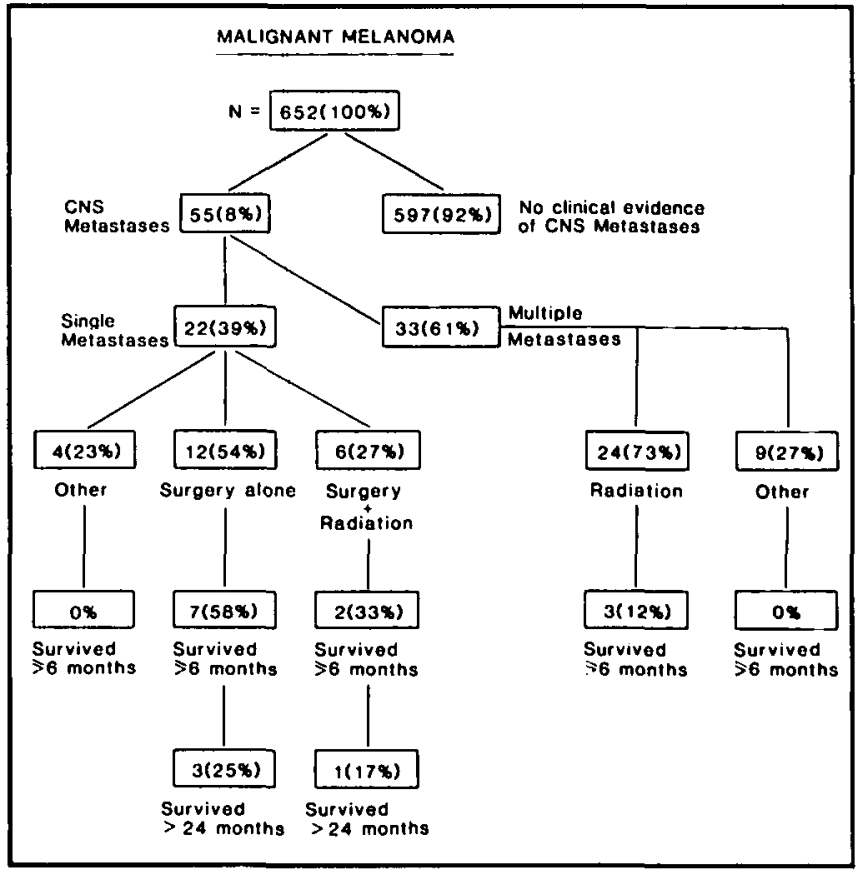

Figure 1 - Flow diagram demonstrating treatment outcome of patients with cerebral malignant melanoma metastases.

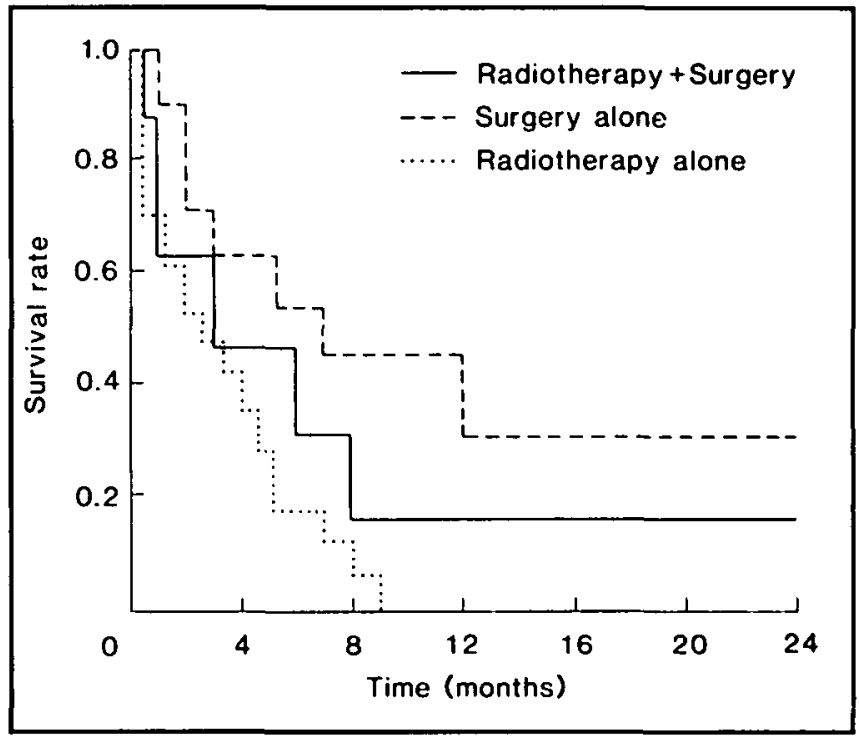

Figure 2 - Kaplan-Meier plots of survival associated with type of therapy. 
influence on the outcome of the disease..$^{13.14}$ However, there are a number of reports of long term survival in patients with solitary lesions treated surgically. ${ }^{8,9,12,15,16,17}$ In the present series, $39 \%$ of the patients had a single metastasis and $61 \%$ had multiple lesions. This distribution is similar to that reported by other investigators. ${ }^{7}$ Seven patients $(58 \%)$ with a single metastasis and treated with surgery alone survived longer than six months; three patients survived more than 24 months. Two of these patients were reoperated on for solitary metastases at different sites. They succumbed with multiple cerebral metastases at 28 and 34 months after initial surgery. A third patient is still alive 64 months after surgical excision of a single metastasis without any subsequent therapy. Two patients (33\%) with single metastases who had both surgical excision and radiotherapy survived more than six months. One of these patients survived 28 months. In this patient, radiotherapy was given following a second operation for recurrence of melanoma at the same site 14 months after initial surgery.

In patients with multiple metastases, median survival after a two week course of Cobalt-60 radiotherapy was 10 weeks which is similar to previous reports. ${ }^{7.18}$ Three patients (12\%) survived more than six months with the longest survival being 9.5 months.

The results of this study support the concept that a subpopulation of patients presenting with a single metastasis and treated with surgery alone or surgery and radiation exists and has a longer survival. Although the number of patients in this subgroup is small, there appeared to be no distinct benefit of the addition of radiation to surgical management. The prognosis of patients with multiple cerebral metastases is poor and the impact of radiation therapy in this group cannot be assessed in a retrospective study of this type. It has been suggested that up to $14 \%$ of cerebral malignant melanoma metastases respond to radiotherapy ${ }^{7}$ and symptomatic improvement has been documented. ${ }^{18}$

Malignant melanoma cells have a very complex radiobiology with growth rate, hypoxic fraction and a number of repair mechanisms all interacting to influence the radiosensitivity of a particular cell line. ${ }^{19}$ A striking heterogeneity of response to radiation is present among individual melanoma cell lines and melanoma multicellular spheroids. ${ }^{19,20}$ It has been suggested that a higher radiation dose per fraction my be superior to conventional fractionation dosage. ${ }^{21}$ This was not substantiated in a clinical trial of cerebral metastases from malignant melanoma. ${ }^{22}$ Our results and those of others suggest that patients with cerebral malignant melanoma metastases may respond poorly to presently available radiation therapy. ${ }^{7,18}$ To achieve improved results, radiation therapy may have to be individualized on the basis of the in vitro radiation response of a patient's own melanoma cells. ${ }^{19,20}$

The production of growth factors by melanoma cells has been reported. ${ }^{23}$ A low molecular weight human transforming growth factor has been identified in the urine of patients with melanoma which competitively binds for epidermal growth factor (ECF) receptors on A431 cells and increases growth in fibroblasts. ${ }^{24}$ Urinary levels of alpha-transforming growth factor $(\alpha-\mathrm{TGF})$ have been reported to be elevated in a patient with cutaneous melanoma and these levels decreased after surgical resection. ${ }^{25}$ Increased levels of $\alpha$-TGF mRNA have been reported in the A2058 melanoma cell line and increased levels of $\alpha$-TGF, $\beta$-TGF and EGF-receptor mRNA have been reported in a surgical specimen of melanoma. ${ }^{26}$ The modulation of various growth factors may be a new approach to the treatment of cerebral malignant melanoma metastases.

The most appropriate management for an individual patient with cerebral metastases from malignant melanoma is determined by a number of important variables. The degree of systemic disease, the number of cerebral metastases and their location will clearly influence any treatment options to be considered. However, in all patients, corticosteroids are useful in reducing the morbidity associated with peritumoural edema ${ }^{7}$ and the prophylactic use of dilantin may decrease the propensity for seizures.

In patients with surgically accessible single or multiple lesions and no significant systemic disease, a surgicai resection of the mass and as much surrounding brain as can be safely removed should be attempted. This approach should decrease the incidence of recurrence at the initial site and may provide a significant symptom free interval. Patients who have undergone removal of a single metastasis and then develop another single lesion at a remote cerebral site should be considered for reoperation if the initial lesion shows no signs of recurrence. If recurrent disease develops at the same site, repeat surgical excision should be considered and a decision can be made as to whether radiation therapy should be used. The majority of patients with a surgically treated single lesion and extended survival will subsequently develop multiple cerebral metastases and radiation may be considered at that point.

In patients presenting with multiple cerebral metastases, radiation therapy may be considered as a palliative measure to help relieve symptoms. ${ }^{18}$ No significant response of cerebral metastases from malignant melanoma to chemotherapy or other experimental modalities has been reported.

An aggressive surgical approach in patients presenting with single or multiple, easily accessible metastases seems justified. The role of radiotherapy in the management of this disease needs to be futher elucidated by the use of careful clinical trials. New and innovative approaches are needed to improve the chemotherapeutic and radiobiological treatment of this disorder.

\section{ACKNOWLEDGEMENTS}

The authors are grateful to the London Regional Cancer Centre clinical trials unit and especially to Frances Whiston for her assistance in this project and to Jo-Ann Dunn for typing the manuscript. Supported by the Brain Research Fund Foundation, Dr. Del Maestro is a recipient of the Ontario Ministry of Health Career Scientist Award.

\section{REFERENCES}

1. Amer $\mathrm{MH}, \mathrm{Al}$-Sarraf $\mathrm{M}$, Baker HL. Malignant melanoma and central nervous system metastases: Incidence, diagnosis, treatment and survival. Cancer 1978; 42: 660-668.

2. Beresford HR. Melanoma of the CNS treatment with corticosteroids and radiation. Neurology (NY) 1969; 19: 59-65.

3. Bullard DE, Cox EB, Seigler HF. Central nervous system metastases in malignant melanoma. Neurosurgery $1981 ; 8: 26-30$.

4. Budman DR, Camacho E, Wittes RE. The current causes of death in patients with malignant melanoma. Eur J Cancer 1978a; 14: 327-330.

5. Leigh A. Melanoma of the central nervous system. Aust. NZ J Surg 1978; 48: 14-16.

6. Stehlin JS Jr, Hills WJ, Rufino C. Disseminated melanoma biologic behaviour and treatment. Arch Surg 1967; 94: 495-501.

7. Byme TN, Cascino TL, Posner JB. Brain metastasis from melanoma. J Neuro-Oncology 1983; 1: 313:317. 
8. Bauman, ML, Thomas PR. Intracranial metastatic malignant melanoma; long term survival following subtotal resection. Southern Med J 1972; 65: 344-346.

9. McCann WP, Weir BKA. Long term survival after removal of metastatic malignant melanoma of the brain. J Neurosurg 1968; 29: 483-487.

10. Caimcross SG, Kim JH, Posner BJ. Radiation therapy for brain metastases. Ann Neur 1980; 7: 529-541.

11. McBride CM. Diagnosis and management of malignant melanoma: some current approaches and controversies. In Seventh National Conference Proceedings pp 581-585 Philadelphia, J. B. Lippincott Co., 1973.

12. Fell DA, Leavens ME, McBride CM. Surgical versus nonsurgical management of metastatic melanoma of the brain. Neurosurgery $1980 ; 7: 238-242$.

13. Hilaries BS, Raben M, Calabrese AS, et al. Value of radiation therapy for distant metastases from malignant melanoma. Cancer 1963; 18: 765-773.

14. Moon JH. Combination chemotherapy of malignant melanoma. Cancer 1970; 25: 468-473.

15. Hafstrom L, Jonsson PE, Stromblad LG. Intracranial metastasis of malignant melanoma treated by surgery. Cancer 1980; 46: 2088-2090.

16. Vieth RG, Odom GL. Intracranial metastases and their surgical treatment. J Neurosurg 1975; 23: 375-438.

17. McNeil DP, Leavens ME. Long term survival with recurrent metastatic intracranial melanoma. J. Neurosurg 1968; 29: 91-93.

18. Carella RJ, Gelber R, Hendrickson F, et al. Value of radiation therapy in the management of patients with cerebral metastases from malignant melanoma. Cancer 1980; 45: 679-683.
19. Rofstad EK. Radiation biology of malignant melanoma. ActaRadiol (Oncol), 1986; 25: 1-10.

20. Rofstad EK. Growth and radiosensitivity of malignant melanoma multicellular spheroids initiated directly from surgical specimens of tumours in man. Br J Cancer 1986; 54: 569-578.

21. Overgaard $J$. The role of radiotherapy in recurrent and metastatic malignant melanoma: A clinical radiobiological study. Int J Radiat Oncol Biol Phys 1986; 12: 867-872.

22. Ziegler JC, Cooper JS. Brain metastases from malignant melanoma: Conventional vs. high dose per fraction radiotherapy. Int J Radiat Oncol Biol Phys 1986; 12: 1839-1842.

23. Richmond A, Fine F, Murray D, et al. Growth factor and cytogenetic abnormalities in cultured nevi and malignant melanomas. J Invest Dermatol 1986; 86: 295-302.

24. Kim MK, Warren TC and Kimball ES. Purification and characterization of a low molecular weight transforming growth factor from the urine of melanoma patients. J Biol Chem 1985; 260: 9237-9243.

25. Ellis DL, Kafka SP, Chow JC, et al. Melanoma, growth factors, acanthosis nigricans, the sign of Leser-Trélat and multiple acrochordons. A possible role for alpha-transforming growth factor in cutaneous paraneoplastic syndromes. N Engl J Med 1987; 317: 1582-1587.

26. Derynck R, Goeddel DV, Ullrich A, et al. Synthesis of messenger RNAs for transforming growth factors $\alpha$ and $\beta$ and the epidermal growth factor receptor by human tumours. Cancer Res 1987; 47: 707-712. 